\title{
0 direito
}

\section{pós-moderno}

\section{INTRODUÇÃO}
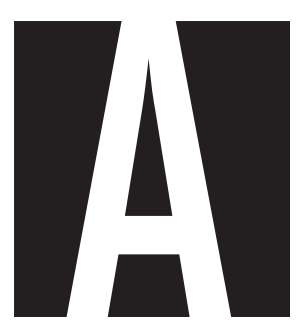

s dúvidas pós-modernas sobre a capacidade da razão para obter noções defini-

tivas, "atingir a essência das coisas", provocam visceral revolta numa ciência tão antiga como o direito, em que a procura

de certeza e objetividade constitui ponto central, “questão de honra", que atravessa milênios - basta pensar no que a Tradição afirma ter sido a causa da Lei das XII Tábuas: a exigência da plebe de que se pusesse por escrito as normas em que os patrícios romanos baseavam suas decisões. Paralelamente, outra característica da pós-modernidade, a hipercomplexidade, no caso, a multiplicidade de grupos sociais, justapostos uns aos outros, dentro da mesma sociedade, cada grupo querendo uma lei especial para si, quebra a permanente tendência à unidade - ao

ANTONIO JUNQUEIRA DE AZEVEDO é professor da Faculdade de Direito da USP. 
"sistema" - do mundo do direito. Em terceiro lugar, finalmente, também a inter-ação, o ir e vir no mesmo nível, semelhante a um mecanismo cibernético, nas atividades da vida social, vai contra a concepção hierárquica - quando não, aristocrática - que o estamento jurídico tem da Justiça.

O jurista vê-se assim, hoje, confrontado com uma realidade que o desgosta; afinal, a razão, com o nome de “motivação”, é exigida em todos os atos do Estado (inciso IX, do art. 93 da Constituição da República: “Todos os julgamentos dos órgãos do Poder Judiciário serão públicos e fundamentadas todas as decisões"; inciso X: "as decisões administrativas dos tribunais serão motivadas") e, agora, vêm filósofos e jusfilósofos "desconstruir" toda essa milenar convicção! No mundo do direito, todos sabem que a lei obriga porque é promulgada por quem tem autoridade (“auctoritas, non veritas, facit legem"), mas faz parte do jogo jurídico comportar-se como se a lei devesse ser obedecida porque é "de razão"; todos sabem também que a decisão judicial se impõe porque é emanada do Poder, mas faz parte do mesmo jogo entender que a sentença é obra "de prudência". Ah, maldita razão que vem destruir a si mesma! Até onde irão um Rorty, com seu neopragmatismo antiessencialista, e um Derrida, com sua desconstrução? O que será do direito?

E aquelas idéias tão elevadas e tão úteis de que a lei é geral, não faz acepção de pessoas e apanha a todos sem distinção? O que há de ser, se cada grupo pretender uma lei para si? Esses consumidores já conseguiram um estatuto especial e aí vêm os negros, as mulheres, os gays, os sem-teto, os sem-terra! Cada grupo quer a sua lei (Minda). Quando se passa ao Poder Judiciário e se sustenta que o juiz deve atender a cada caso concreto, que sentido tem 
lutar por um texto abstrato, o texto da lei?

Em terceiro lugar, o direito sempre foi um sistema, o sistema jurídico; como em todo sistema, há - pensemos numa célulaelementos diversos, cada qual com sua função. Na sociedade, surgido um conflito, o advogado do autor, órgão de input, introduz o conflito no sistema; este, depois de o trabalhar, juntamente com as alegações do réu, soluciona-o peloórgão de output, o juiz. Mas, e agora, quando as partes resolvem os conflitos por conta própria, com arbitragem, ou quando outros poderes "liquidam" bancos e empresas, ou quando provimentos de órgãos paralelos - Bolsa de Valores, Justiça Desportiva, Conselho de Medicina ou OAB - resolvem os casos à margem do Poder Judiciário? Será o fím do sistema?

A pós-modernidade, debaixodessas três características - crise da razão, hipercomplexidade, com justaposição das diversidades, e inter-ação-, perceptíveis também na arquitetura, na literatura, na filosofia, nas comunicações e até mesmo nas ciências exatas, atingiu em cheio o direito.

\section{MUDANCAS DE PARADIGMA}

As difundidas idéias de Kuhn sobre as revoluções científicas e as alterações de paradigma não são conhecidas no mundo jurídico; numa espécie de compensação, também o que se passa no mundo jurídico parece correr ao largo das preocupações dos historiadores da ciência. No entanto, se há um campo em que tudo parece adequado ao pensamento de Kuhn é justamente o do direito. Sendo os paradigmas "modelos de problemas e soluções para uma comunidade de operadores", parece que, por natureza, é isso que ocorre no mundo jurídico; os operadores do direito (juízes, advogados, promotores) passam, de geração em geração, o conhecimento de casos de conflito entre membros da sociedade e transmitem, uns aos outros, como esses casos, juridicamente, podem ser resolvidos. A própria norma não deixa de ser, em cada época, a expressão consolidada de um conflito e de sua solução.
Ora, sem remontarmos a épocas mais remotas, qual era o paradigma até aproximadamente a Primeira Guerra Mundial? Era o paradigma da lei. Vindo dos traumas do absolutismo, o jurista de então via, na lei, o direito. Para dar segurança, a norma devia ser clara, precisa nas suas hipóteses de incidência, abstrata, universal. Como garantia de impessoalidade, o papel do juiz, por isso mesmo, era visto como passivo (o juiz era somente a boca da lei, "la bouche de la loi" - Montesquieu); a sentença, um mero silogismo, cuja premissa maior era o imperativo hipotético do texto legal ("se A é, segue-se B" - se matar, pena de prisão); a premissa menor, o fato ("A é", ou seja, fulano matou) e a conclusão, a decisão (logo, "segue-se B" - fulano deve ser preso). A função do juiz era de um autômato; bastava verificar se havia ocorrido o fato previsto na lei e, se sim, impor a consequiência. As preocupações lógico-formais sobre a lei eram, então, tão grandes que, na vida acadêmica, a "apoteose final" das teses consistia na apresentação de impecável definição de um instituto jurídico, seguida da sugestão de um projeto de lei.

Como salienta Kuhn - e isso ocorria nessa época -, são, porém, as anomalias ou as violações das expectativas que exercem forte atração na comunidade científica, prenunciando crise. Não é, pois, de admirar que questões estatisticamente insignificantes tenham merecido tanta atenção: como resolver os casos de lacuna da lei? o costume obriga? Para essas indagações, os juristas de então gastaram, como se diz, rios de tinta; afinal, essas situações punham em xeque o paradigma de que estava na lei a solução para os conflitos que os juristas deveriam resolver. E lei, vale dizer, era a lei estatal, a lei positiva - não princípios religiosos ou de direito natural.

Após a Primeira Guerra Mundial, a generosidade de alguns espíritos, preocupados com uma justiça mais efetiva, e também a ambição política de outros, menos altruístas, desejosos de ver o Estado agindo sem peias, levaram à visão de que a lei - rígida, inflexível, alheia à diversidade da vida - era um obstáculo a ultrapassar. O 

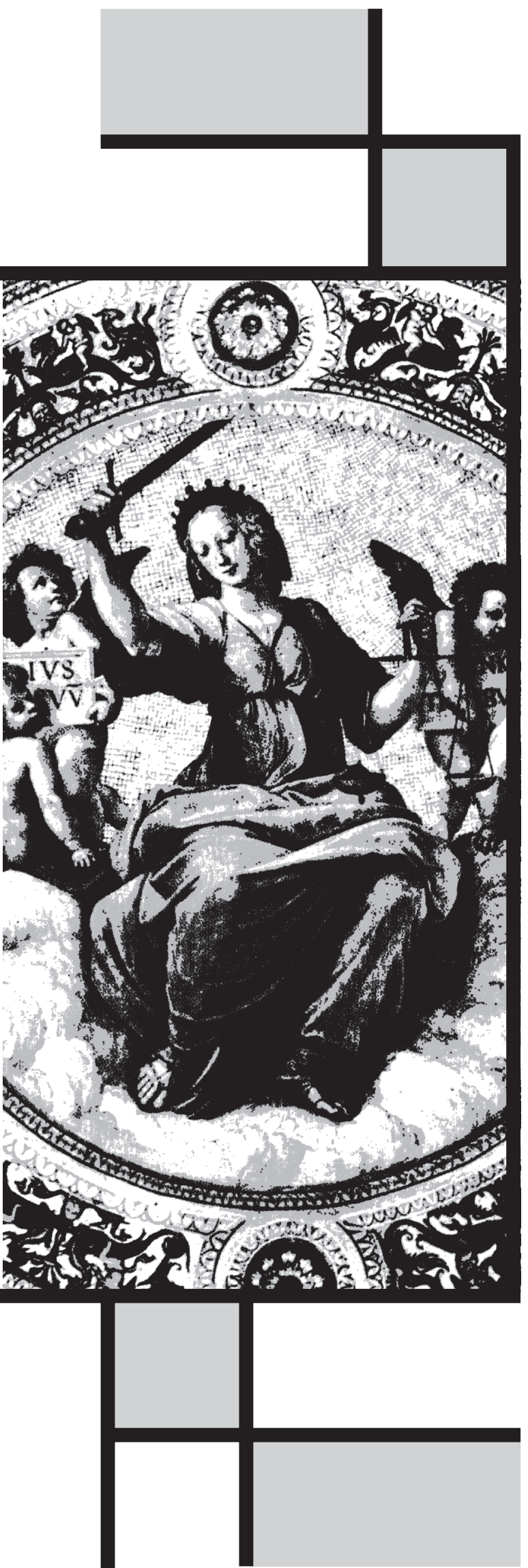

paradigma termina, pois, por mudar; o jurista deixa de examinar as questões pelo ângulo da lei e passa a tomar, nos seus modelos de solução, como centro, a figura do juiz, (um representante do Estado). Introduziram-se, assim, nos textos normativos, os conceitos jurídicos indeterminados, a serem concretizados pelo julgador, e as cláusulas gerais, como a de boa fé (falouse até mesmo em fuga para as cláusulas gerais, ou seja, fuga da lei para o juiz). Noções vagas, como ordem pública, interesse público, função social, tornaram-se moeda corrente no mundo jurídico, servindo a torto e a direito para as autoridades de plantão. Multiplicaram-se, na doutrina, os trabalhos sobre o papel do juiz, sua função, sua independência, sobre o modo como deve interpretar, etc. Diante do novo paradigma, é claro que alguns permaneceram aferrados ao paradigma antigo, tal e qual, hoje, outros tantos, por seu turno, continuam presos a este paradigma que ora estamos descrevendo e que podemos chamar de paradigma da modernidade (por oposição ao atual, da pós-modernidade).

Examinando a questão pelo ângulo universitário, até mesmo a importância das disciplinas jurídicas se alterou. Se, no tempo do que aqui apresentamos como primeiro paradigma, eram fundamentais o direito civil e o direito comercial, na época do paradigma moderno, ocuparam a cena o direito processual e o direito administrativo; seriam estes, então, as "ciências de ponta", como se diz no jargão científico.

Pois bem, atualmente, se o mundo jurídico, ao invés de se alarmar com o que se passa, procurasse entender que estamos, outra vez, simplesmente, a mudar de paradigma, talvez não se revoltasse tanto e passasse, singelamente, a perguntar: hoje, qual é a situação?

\section{O PARADIGMA PÓS-MODERNO}

O tempo que estamos a viver, em primeiro lugar, não se conforma com as noções vagas que tudo fazem depender do 
juiz nem, por outro lado, deseja uma volta ao passado com a lei abstrata e geral.

Antes de mais nada, é preciso compreender que o direito, na verdade, não é em si um sistema autônomo; integrado na sociedade, ele é um sistema de segunda ordem, algo assim como o sistema nervoso nos seres vivos (Maturana e Varela). Por isso mesmo, para cumprir sua função de absorver conflitos sem perturbar o grande corpo social, ele tem, justamente, de dar solução aos conflitos, da melhor forma possível. Ora, para cumprir seu papel não há necessidade de, sempre, tudo levar ao juiz; este pode não ser o melhor caminho. Aos poucos, os grupos sociais descobrem outras soluções. Da fuga para o juiz, cabe hoje falar em fuga $d o$ juiz - e isso, diga-se, não diminui o Poder Judiciário, eis que este fica limitado a agir nas hipóteses em que, de fato, é necessário como julgador. Para que juiz, em casos nos quais as partes admitem um árbitro? Para que juiz, para resolver, "rescindir", um contrato ou para alterar um pacto antenupcial? (Aliás, no último caso, cá no Brasil, nem à solução do juiz chegamos.) A existência pluralista de organismos que decidem com base em seus próprios códigos deontológicos (por exemplo, conselhos de ética de advogados, médicos, publicitários) ou a de entidades como a Justiça Desportiva e a Bolsa de Valores ou, ainda, a de instituições que possuem suas próprias normas e órgãos decisórios (por exemplo, as universidades), ao invés de assustar o jurista ("Agora, nada depende da lei e do juiz”!), deve levá-lo a reconhecer a especificidade de cada situação. A lei e o juiz ficarão para os casos extremos. O paradigma jurídico, portanto, que passara da lei ao juiz, mudou, agora, do juiz ao caso. A centralidade do caso, é este o eixo em torno do qual gira o paradigma jurídico pós-moderno.

Do ponto de vista teórico, não precisa o professor, apavorado, afirmar, mais para si mesmo que para os discípulos, que a unidade do sistema não está perdida, porque há a Constituição e que essa cúpula "fecha o sistema"! A frase é ilusória porque, na verdade, a Constituição é composta de muitos princípios e estes precisam ser desenvolvi- dos, “desenrolados", por interpretação. A Constituição não é por si essa tábua de salvação de uma pretensa "reductio ad unum"; ela, como todos os textos, exige leitura e permite muitos entendimentos e aplicações.

Por outro lado, ao afirmar que as noções vagas estão ultrapassadas, pode-se até mesmo vislumbrar uma certa volta a aspectos do paradigma da pré-modernidade - no caso, à preocupação com a segurança jurídica. Aliás, o próprio direito civil voltou a ser disciplina jurídica de ponta; é ele que, hoje, por ter como objeto a vida e, em especial, a vida humana, dá sentido à própria Constituição. As noções vagas de ordem pública, interesse público e função social - muletas para o juiz e as autoridades, no paradigma anterior - já não satisfazem. Continuam a ser, não resta dúvida, muito numerosas as leis ditas de ordem pública, especialmente, as relativas à ordem pública de proteção, por oposição às da ordem pública de direção; todavia, deixando de lado as leis cogentes, isto é, tomando-se a ordem pública exclusivamente como princípio, para fundamentar a nulidade de determinado ato ou para justificar a validade de outro, ela somente tem cabimento, nos novos tempos, em uma única hipótese: como proteção à dignidade humana; fora disso, não tem mais aplicação. Ocorre algo parecido com a noção de interesse público; basta lembrar, para verificação de quanto o novo paradigma repele as noções vagas, as alegações de ex-ministros, feitas pela imprensa nos dias que correm, de que providências a favor, ou contra, determinados concorrentes em leilão de telefonia, visavam o interesse público; qualquer um percebe o inconveniente da falta de conteúdo dessa expressão. O novo paradigma exige, pois, vetores materiais, idéias ordenadoras, diretrizes, e não fórmulas vazias, próprias de uma axiologia formal, cujo "recheio" é posto arbitrariamente pela autoridade (juiz ou membro do Poder Executivo). Para a expressão "função social”, por sua vez, os próprios constituintes de 1988, no espírito da pós-modernidade, ainda que, como é óbvio, alheios ao que se faz teoria, deram vetores materiais 
para sua caracterização (ver art. $182, \S 2^{\circ} \mathrm{e}$ art. 186 da Constituição).

Resta a questão das dúvidas pós-modernas sobre o trabalho da razão. Após um primeiro susto, os muitos séculos de história do direito deveriam levar o jurista a aplaudir as tentativas de desconstrução. A História comprova a existência de mudanças e, por outro lado, nada melhor para a realização da Justiça que a tomada de consciência do que está subjacente à lei ou à sentença. O reconhecimento da precariedade da razão, se, de um lado, leva à nãoadmissão de dogmas racionais (os dogmas racionais, de resto, não se confundem com os dogmas de fé e moral, que têm outros fundamentos), de outro, não impõe a conclusão de que estamos a viver a consagração do irracionalismo. Verificada a fragilidade da razão, deve o jurista, ao invés de afastá-la, colocar a seu lado, como um arrimo, a intuição do justo. Afinal, interpretar, como revelam alguns profundos trabalhos de hermenêutica (Coreth, Grondin), não é apenas "entender intelectualmente", é também intuir - especialmente no caso do direito, em que o objetivo final é resolver os problemas existenciais da pessoa humana no seu relacionamento recíproco. Saudemos, pois, o direito pós-moderno.

\section{BIBLIOGRAFIA}

CORETH, Emerich. Questões Fundamentais de Hermenêutica. Trad. de Carlos Lopes de Matos. São Paulo, Edusp, 1973. DERRIDA, Jacques. Du Droit à la Philosophie. Paris, Galilée, 1990. e CAPUTO, John. Deconstruction in a Nutshell. New lork, Fordhan University Press, 1997.

GRONDIN, Jean. L'Horizon Herméneutique de la Pensée Contemporaine. Paris, Vrin, 1993.

KUHN, Thomas S. The Structure of Scientific Revolutions. 3ed., Chicago, The University of Chicago Press, 1996. MATURANA, Humberto R. e VARELA, Francisco J. The Tree of Knowledge. Boston, New Science Library, 1988. MINDA, Gary. Postmodern Legal Movements. New lork, New York University Press, 1995.

RORTY, Richard; HABERMAS, Jurgen e KOLAKOWSKI. Debating The State of Philosophy. Westport-Connecticut, Praeger, 1996.

RORTY, Richard. Truth and Progress. Cambridge, Cambridge University Press, 1998. 